
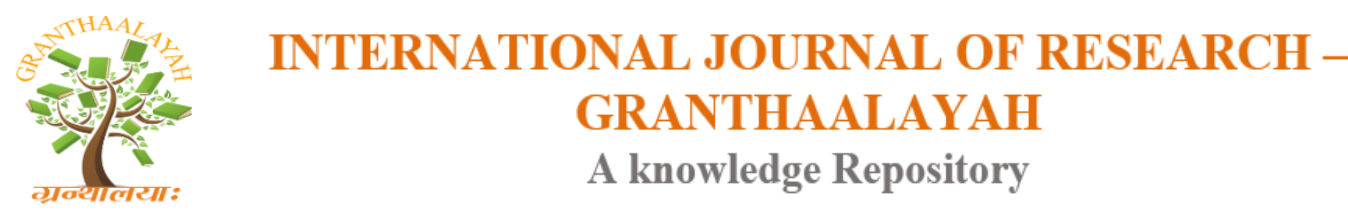

Management

\title{
TECHNOLOGY INNOVATION IN BANKS - NEED FOR OMNI- CHANNEL SERVICES
}

\author{
Dr.K.Vijaya Venkateswari ${ }^{* 1}$ \\ ${ }^{*}$ Associate Professor, Department of Commerce, Sri Ramakrishna College of Arts and Science \\ for Women, Coimbatore, India
}

\begin{abstract}
Technological Innovations have the potential to continue to significantly transform the financial services industry and benefit society. They can replace individual banks' legacy systems, enhance processes, improve efficiencies and strengthen controls. They can also provide opportunities for the creation of new products and services that benefits customers. Ultimately, technological innovations hold great promise for the identification of new customers and the provision of financial services to the unbanked or under banked community in a safe and sound manner. This paper aims at studying the need for Omni-channel services and the benefits of digitalisation in banking services.
\end{abstract}

Keywords: RPA (Robotic Process Automation); KYC (Know Your Customer; DLT (Distributed Ledger Technology); SOA (Service Oriented Architecture).

Cite This Article: Dr.K.Vijaya Venkateswari. (2018). "TECHNOLOGY INNOVATION IN BANKS - NEED FOR OMNI-CHANNEL SERVICES." International Journal of Research - Granthaalayah, 6(1), 150-155. https://doi.org/10.29121/granthaalayah.v6.i1.2018.1604.

\section{Introduction}

If the last era in retail banking was defined by a boom-to-bust expansion of consumer credit, the current one will be defined by digital. This will include rapid innovation in payments and the broader transformation in systems enabled by digital technologies. The urgency of acting is acute. Banks have three to five years at most to become digitally proficient. If they fail to take action, they risk entering a spiral of decline similar to laggards in other industries. Revenues and profits will migrate at scale toward banks that successfully use digital technologies to automate processes, create new products, improve regulatory compliance, transform the experiences of their customers, and disrupt key components of the value chain. Institutions that resist digital innovation will be punished by customers, financial markets, and sometimes regulators. Banks increasingly realize that to succeed with digital, they must adopt the habits and culture of digitally native companies. We expect no letup in the pace of change. Within the next five years, digital sales have the potential to account for a good percentage of new inflow revenue in the most progressive geographies and customer segments. In the forthcoming years banks in India 
are forecast to have more revenue in most products coming from digital sales. Banks have just a few years to adapt digital transformation. Appreciating the magnitude of the opportunity and the gravity of the threat is vital, but it is just the first step in formulating a winning digital strategy. Digital will touch every aspect of bank operations, from product development to risk management and human-capital management. Successful strategies need to be based on a clear understanding of how digital creates value, granular perspectives on consumer behaviour and market dynamics, and careful prioritization by top management among hundreds of potential digital investments.

\section{Objectives of the Study}

1) To study the benefits of Digitalisation in banking services.

2) To identify the need for Omni-channel services.

3) To suggest ways through which Omni-channel strategy can be adopted.

\section{Methodology}

This study is a descriptive one. This study was conducted to find out the need for Omni-channel services in banks and to study the benefits of digitalisation in banking services.

\subsection{Data Source Used}

The present study is based on secondary data. The required information have been derived from articles, Journals and from the various related web-sites which deal directly or indirectly with the topics related to modern banking services.

\subsection{Limitations of the Study}

1) The study is based on published data and information. No primary data is being used.

2) Secondary data may be lacking in accuracy, or they may not be completely current or dependable.

\section{Benefits of Digitalisation in Banking Services}

\subsection{Increase liveliness and Speed to Market}

Ongoing adoption of digital-era technologies has accelerated the pace of change within the banking industry and beyond. New entrants to the banking ecosystem are rapidly developing and demonstrating the feasibility of digitally enabled end-to-end business models. Technological innovations are expediting the transformation of bank technologies and enterprise architecture.

\subsection{Technology and Operations Configured for Business Agility}

Nonbank entities; start-ups; and large, established technology companies have demonstrated that digital infrastructure and platforms have the potential to meet stringent, technical resiliency and stability requirements. Adopting and/or integrating digital platforms within existing 
infrastructure enables banks to accelerate resource provisioning, achieve scalability and preserve development agility for business and IT resources to drive the business forward in a controlled and resilient manner.

\subsection{Digital Business Models that is More Responsive to Changing Customer, Market and Regulatory Dynamics}

The shift toward digital platforms allows banks to interact more closely with customers, and quickly design and deliver relevant services. Digitizing end-to-end business processes further enables banks to achieve scale and become more efficient, resilient and transparent. As a result, banks are better able to quickly respond to changing customer needs.

\subsection{Growth in Transaction Volume}

Digitally enabled providers can scale their offerings as customers and transaction volumes grow. For example, robotics and analytics minimize manual processes, allowing firms to efficiently process documentation related to customer on boarding and servicing etc.

\subsection{Biometric Authentication}

Identity and access management coupled with IT, enable bank managers and security officers to receive automated alerts about suspicious customer activity to protect against identity theft and fraud.

\subsection{Voice Recognition}

Voice recognition and analytics enable real-time automated identification of suspected fraudsters, preventing repeat offenders from receiving services over the phone.

\subsection{Data Analytics}

Analytics monitor patterns of normal activity and both detect and alert users to discrepancies reducing fraud and improving risk management.

\subsection{Improve Operational Efficiency and Transparency}

Digital surveillance platforms embedded with natural language processing offer cost-efficient and effective solutions for monitoring various communication mediums that were previously difficult to examine. Such technology could be used to detect and prevent potential market manipulation by traders.

\subsection{Enhance Institutional and Market Efficiency}

Banks and financial market utilities are currently evaluating the use of DLT to potentially increase efficiencies, better manage risk, and/or standardize intercompany processes. 


\subsection{Improve Bank Cost Efficiency}

Digital technologies are helping banks to move toward more modern, sophisticated, scalable and cost-effective platforms. RPA and analytics are being used to drive significant and sustainable productivity enhancements through automation.

\section{Need for Omni-Channel Services}

Traditionally, banks spent most of their efforts, time and money on transaction execution, which is nothing but has become a very basic feature of their overall service. While providing expedient, consistent and precise transaction processing ability is still critical, we believe that banks can learn from how retailers see the customers' journey through an Omni-channel lens. Banks now need to rethink the way customers are being valued, may be from the angle of the industries that greatly value customer experience. A tightly coupled multichannel may provide a share of customer's pocket, but successful implementation of Omni-channel can surely increase the size of the share though competitive advantage and also can help them to retain the same share for a longer period of time. Customers from all generation, income groups, and countries could make a transaction online one day, and another day, the same transaction through mobile or ATM - or they could start a transaction on any of these channels then continue on another and finish it on different channel. Multichannel gives the flexibility to hop between channel, but not the continuation of the transactions among multiple channels. So, this represent a remarkable challenge for the financial institutions, which are often involved in multiple types of banking such as retails, finance, corporate, mortgage etc...

The most effective way to understand and bring the organization from traditional banking to digital banking is Omni-Channel approach. Omni-channel is a multichannel approach to customer service where all the channels are tightly integrated, keeping customer in the center of the integration. As customers continue to change their channel usage patterns, banks and credit firms need to focus on delivering a seamless customer experience across various touch points. More than just an axiom, Omni-channel banking is a prospect to take bottom-line on higher note by gaining insights from customers' channels, behaviour and preferences. Today's customers are more sophisticated and tech savvy, and to cater to their specific needs, each customer needs a unique experience from banking. From researching new services, opening an account, checking balance, conducting transactions, loans, credits, wealth management, customer support, delivering an Omni-channel experience has become a key to success in this competitive market place.

Omni-channel is not the replacement of multichannel, but it's the enrichment. Espousal of Omnichannel is indispensable to ensure that customer experience is unified, incorporated and supports customer at the right time, in the right place as the right way. It must be as per their mobile and digital life style. Staying connected in current banking revolution entails deep acquaintance of customers' needs, wants and demands. It also requires the precise mixture of IT infrastructure and innovative new technologies to certify that one remains ahead in current market space to drive top, as well as bottom lines upwards. An Omni-channel strategy brings all the key parameters - online and offline channels, data and technology, customer behaviour and experience - all, onto one platform. Omni-channel does not replace multichannel, but, instead, 
enhances it. Multichannel remains an essential foundation to a comprehensive Omni-channel experience.

\section{Strategy for Adopting Omni-Channel}

Banks must adopt a three-tiered approach to build an Omni-channel presence i.e, capturing customers' intent, managing systems of engagements and deriving and utilizing actionable insights.

- Capturing: Banks shall utilize different channel analytics techniques to capture the intent behind interactions across channels with customers' consent. In contact centers, customers' emotion can be analyzed using speech analytics. On social networks, sentiment can be understood using social sentiment analytics technologies.

- Managing: The intent captured across channels will be in all kinds of forms. Some are structured, while others are unstructured, such as video, audio and free-form text. These are often less than 100-percent accurate and fuzzy in nature. They must be stored and managed separately in a system of engagements from the structured, trusted system of records.

- Analyzing: Today, Big Data technologies are mature enough for banks to derive actionable insights reliably and quickly. These insights enrich the understanding of customers and can be invaluable for banks to provide intelligent and differentiated services, as well as more targeted marketing offers.

\section{Conclusion}

As customers become increasingly comfortable with technology, they are interacting with banks in multiple ways. Unlike customers in days gone by, these enlightened and empowered consumers will not accept "cookie-cutter" treatment. Having a solid multichannel infrastructure and providing an Omni-channel experience allows customers to enjoy seamless, personalized service across every touch point. As the world becomes even more digital, capitalizing on the Omni-channel opportunity could be the difference between those banks that flourish in the coming years and those that can no longer compete.

As of today, various channels are working in their silos, but it's time to break their silos and renovate the banking experience by instigating Omni-channel strategy. This approach is based on a single brand name, providing customer centric experience to each and every customer as per their preference and behavior just like an individual bank for every customer - and so smoothly transacted that it becomes seamlessly embedded in the customer's lifestyle. Today's demand of banking is: anytime anywhere banking. This requires innovative, robust, secure, optimized and ready to meet the expectations of empowered and tech-savvy customers.

\section{References}

[1] https://www.mckinsey.com/industries/financial-services

[2] https://www.happiestminds.com 
[3] https://www.ibm.com

[4] http://www.idrbt.ac.in/assets/publications

[5] Aruna R. Shet, (2015) Technological Innovations in Indian Banking Sector, International Journal of Scientific Engineering and Research (IJSER), ISSN (Online): 2347-3878, pg.11-14

\footnotetext{
*Corresponding author.

E-mail address: vijicommerce67@ gmail.com
} 